\title{
Low Power Low Jitter 0.18 CMOS Ring VCO Design with Strategy based on EKV3.0 Model
}

\author{
Amine AYED and Hamadi GHARIANI \\ LETI Laboratory-ENIS \\ Sfax, Tunisia
}

\begin{abstract}
In this paper, the design of micro-power CMOS ring VCO with minimum jitter intended for a concept of frequency synthesizer in biotelemetry systems is studied. A design procedure implemented in MATLAB is described for a circuit realization with TSMC $0.18 \mu \mathrm{m}$ CMOS technology. This conventional design methodology based on EKV3.0 model is clearly suited to the challenges of analog circuits design with reduced channel width. Measures realized with ADS confirmed methodology capability to circuit sizing respecting the specifications of application. The designed ring VCO operates at a central frequency of $433 \mathrm{MHz}$ in ISM band with an amplitude of oscillation equal to $500 \mathrm{mV}$. The integration area was intrinsic (without buffers and without external capacitances). The simulated phase noise is about $-108 \mathrm{dBc} / \mathrm{Hz}$ at $1 \mathrm{MHz}$, the value of rms jitter is $44.8 \mathrm{ps}$ and the power consumption of the designed VCO is $6.37 \mathrm{~mW} @ 433 \mathrm{MHz}$.
\end{abstract}

Keywords-Ring VCO; jitter; power consumption; EKV model; MATLAB

\section{INTRODUCTION}

An overview of some frequency synthesizers required for implantable biotelemetry systems cited in the literature would be presented in this section.

The full-divider frequency synthesizer shown in [1] generates two local oscillator (LO) signals at $1 / 3$ and $2 / 3$ of the central frequency of $5240 \mathrm{MHz}$. This fully integrated $0.25 \mu \mathrm{m}$ CMOS synthesizer includes a programmable loop filter and a VCO offering an $800 \mathrm{MHz}$ adjustment range through a switchable capacitor bank. The synthesizer has a very low phase noise of $-105 \mathrm{dBc} / \mathrm{Hz}$ at $10 \mathrm{kHz}$. However, this performance was accompanied by a very high power consumption of $93 \mathrm{~mW}$.

A fully integrated synthesizer compatible with the ZigBee standard and implemented in a $0.18 \mu \mathrm{m}$ CMOS process was presented in [2]. This circuit includes a third order passive loop filter. The VCO generates I/Q quadrature signals and the frequency divider was implemented using current-mode logic. The power consumption is $22 \mathrm{~mW}$ at a supply voltage of $1.8 \mathrm{~V}$.

An entire divider CMOS synthesizer operating at $1 \mathrm{~V}$ supply voltage was presented in [3]. The VCO is based on the architecture implemented in $0.18 \mu \mathrm{m}$ CMOS technology. The circuit uses a transformer in the feedback branch. Its power consumption is $10 \mathrm{~mW}$. The measured phase noise is -139 $\mathrm{dBc} / \mathrm{Hz}$ at $20 \mathrm{MHz}$ from the carrier of $4.256 \mathrm{GHz}$. The synthesizer offers a tuning range of 4.114 to $4.352 \mathrm{GHz}$ for 16 channels.

The synthesizer manufactured in 90-nm CMOS technology operating in the Industrial Scientific and Medical (ISM) band of 902-928 MHz was presented in [4]. This synthesizer based on a PLL allows the selection of seven channels and provides differential I/Q signals. The total measured consumption of the synthesizer is $640 \mu \mathrm{W}$.

Referring to the bibliography study, The VCO can be considered as the most important building blocks in the structure of frequency synthesizers based on the use of PLL. The VCO circuit is a critical component that significantly affects the performances of PLL in terms of phase noise, timing jitter and power consumption.

This work proposes a CMOS design of differential architecture of ring oscillator operating in ISM band. In Section II of this paper, the topology and characteristics of ring oscillators were exposed. In Section III of this paper, an innovative methodology approach based on EKV3.0 modeling for low power VC0 design was presented. Finally, simulations results and a comparative study with other works were exposed in Section IV.

\section{RING VCO TOPOLOGY}

The topology of the proposed VCO is based on the principle of cascading four delay cells with an inversion in the loop as shown in Fig. 1.

Each cell represents a differential nMOS pair (M5 and M6) with linear loads called Maneatis loads [5] consisting of the paralleling of a linear pMOS (M3 / M1) with a pMOS of the same size connected in a diode (M2 / M4) as shown in Fig. 2. The control of the oscillation frequency was realized as follows.

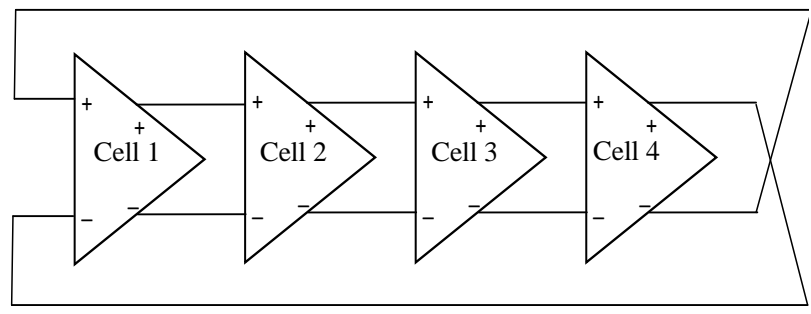

Fig. 1. Ring VCO topology. 


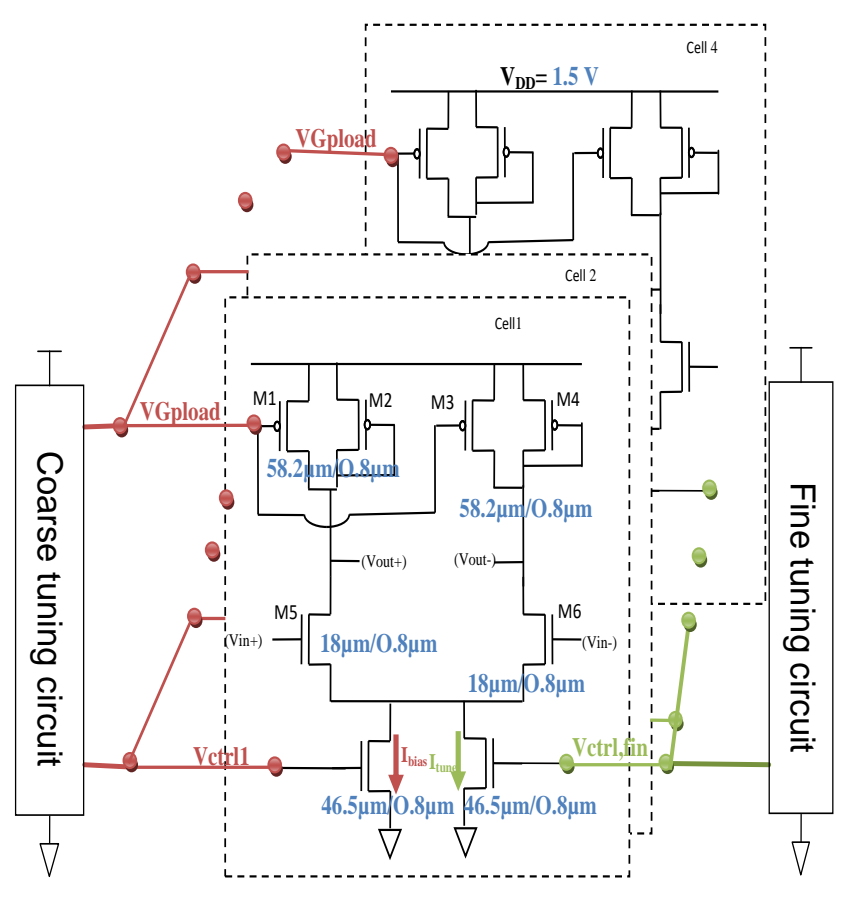

Fig. 2. Circuit of dual frequency - controlled CMOS ring VCO.

The coarse tuning circuit sets the gate voltage of the load pMOS $\mathrm{V}_{\text {Gpload }}$ so that with a current $\mathrm{I}_{\text {bias }}$ passing through the load, a voltage difference equal to $\mathrm{V}_{\mathrm{sw}}$ occurs across its terminals representing the oscillation amplitude. This setting provides a wide frequency range by acting on the current $\mathrm{I}_{\text {bias }}$ while keeping $\mathrm{V}_{\mathrm{SW}}$ constant.

The fine tuning circuit allows more precise control of the frequency by means of a differential voltage $V_{\text {contrl,fin }}$ controlling the injection of an additional current $I_{\text {tune }}$ into each cell.

The expression of the oscillation frequency is given by:

$$
f=\frac{1}{2 \mathrm{NR}_{\mathrm{L}} \mathrm{C}_{\mathrm{m}}}
$$

Where, $\mathrm{N}$ is the number of cells of the ring oscillator, $\mathrm{R}_{\mathrm{L}}$ and $\mathrm{C}_{\mathrm{m}}$ being respectively the equivalent resistance and capacitance seen at the output nodes.

The cell gain is computed as:

$$
\mathrm{Av}=\mathrm{gm}_{\mathrm{m}} \mathrm{n} \mathrm{R}_{\mathrm{L}}=\mathrm{gm}_{\mathrm{m}, \mathrm{n}} \frac{\mathrm{VDD}-\mathrm{V}_{\text {outdc }}}{\mathrm{Ibias} / 2}=\left(\frac{\mathrm{gm}}{\mathrm{I}_{\mathrm{D}}}\right)_{\mathrm{n}}\left(\mathrm{VDD}-\mathrm{V}_{\text {outdc }}\right)
$$

Where, $g_{m, n}$ is the gate transconductance of $n M O S$ transistor and $\mathrm{V}_{\mathrm{DD}}$ is the supply voltage.

The expression of the VCO jitter is given by:

$$
{\overline{\Delta \mathrm{t}_{\mathrm{VCO}}}}^{2}=\mathrm{T}_{0}\left(\frac{\mathrm{I}_{\text {bias }}}{\mathrm{C}_{\mathrm{m}} \mathrm{V}_{\mathrm{SW}}}\right) \cdot \frac{\mathrm{KTC}_{\mathrm{m}}}{2 \cdot\left(\mathrm{I}_{\text {bias }}\right)^{2}} \cdot\left(\mathrm{A}_{\mathrm{V}} \cdot \xi\right)^{2}
$$

Where, $\xi$ represents noise factory contribution.
Notice that all capacitances and drain currents associated to transistors would be evaluated in the next section by the use of the EKV 3.0 model [6] giving continuous expressions from weak to strong inversion.

\section{Dimensioning Algorithm of VCO}

In this section, the modeling of the MOS transistor was developed by means of the EKV3.0 model [6].

Consider the half-pair of the differential cell to be dimensioned shown in Fig. 3 after replacing the current mirror by a constant current source delivering current $\mathrm{I}_{\mathrm{B}}$. The VCO differential cell sizing program was implemented on MATLAB following the design plan shown in Fig. 4. The design plan begins by setting the value of $\mathrm{V}_{\mathrm{DD}}$ to reach. Then the resolution goes through a scan in dimensions to find the solutions compatible with the specifications. Here, an oscillation frequency equal to $433 \mathrm{MHz}$ is required, the value of $\mathrm{V}_{\mathrm{SW}}$ was fixed at $1 \mathrm{~V}$ and the gain of the cell $\mathrm{Av}$ was fixed at 1.5 .

These parameters related to the circuit specifications were declared at the beginning of the program. The lengths of the transistors were also initialized to the same value $0.8 \mu \mathrm{m}$.

This first step of data declaration ends with the introduction of some technological parameters of the transistors which were needed to evaluate the jitter, the intrinsic and extrinsic capacitances involved in the calculation of the total load capacitance seen at the output of the delay cell.

Now, using the results of the identification algorithm discussed in [7], the EKV parameters of the transistors were declared in a three-dimensional space $\left(\mathrm{V}_{\mathrm{D}}, \mathrm{V}_{\mathrm{S}}, \mathrm{L}\right)$. The sizing space in this program was defined in 2D by means of the log vectors $\mathrm{q}_{\mathrm{F} 1}$ and $\mathrm{q}_{\mathrm{F} 2}$ varying on a logarithmic scale.

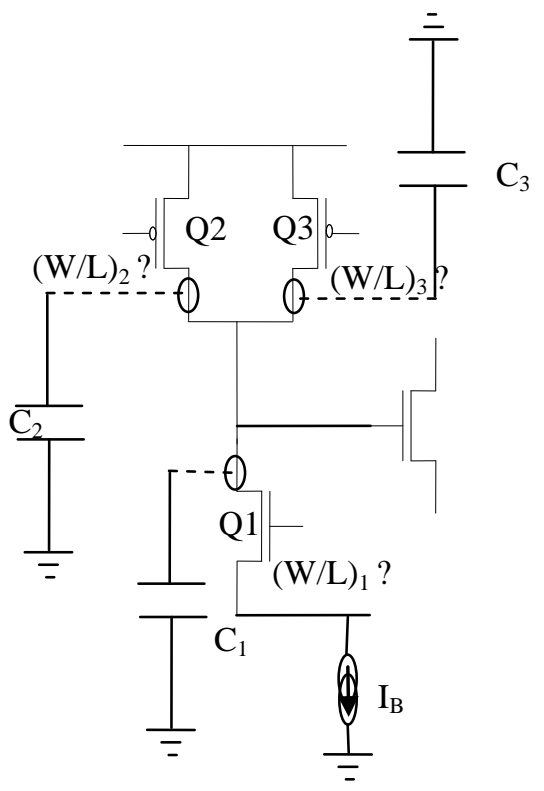

Fig. 3. The half-pair differential cell with equivalent capacitances seen at the output node. 


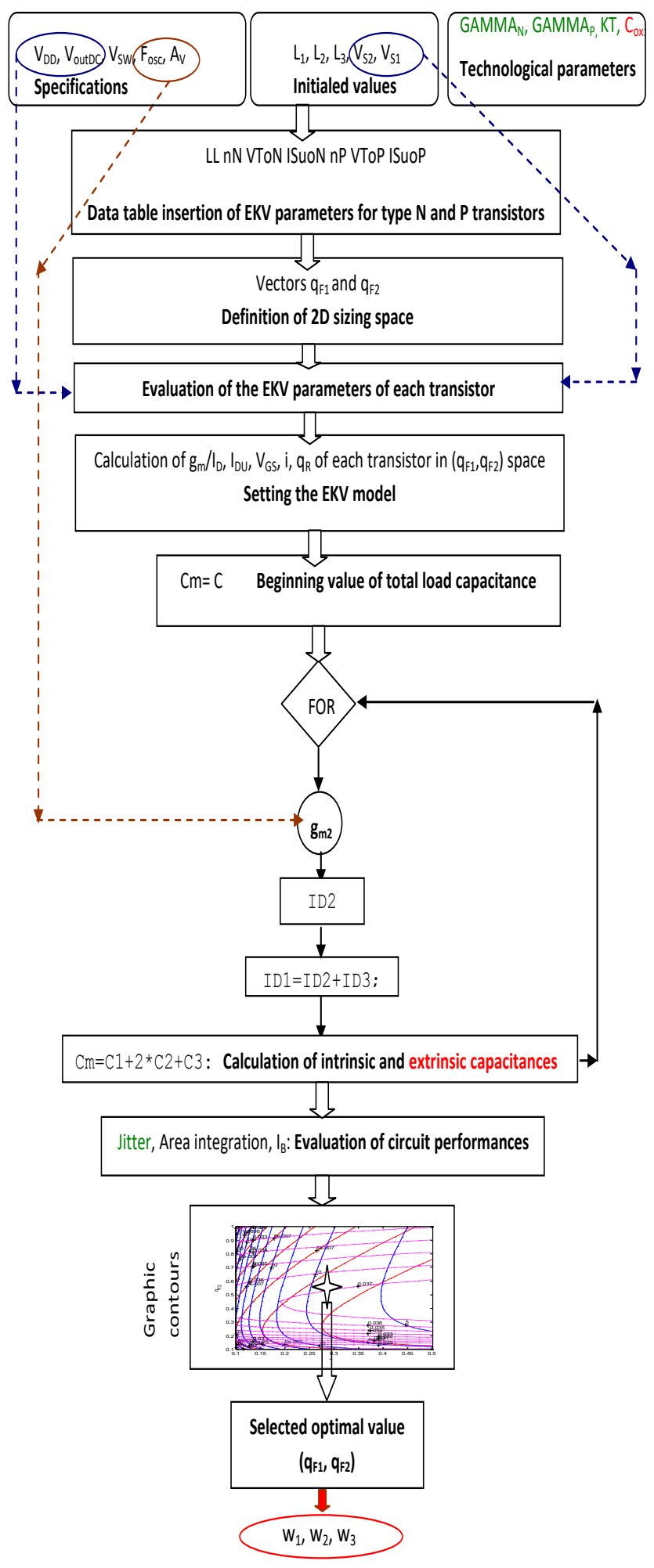

Fig. 4. Algorithm design for cell VCO dimensioning.
In the next step, the evaluation of the EKV parameters of each transistor in the dimensioning space was chosen according to their polarization levels. For the pMOS transistor $\mathrm{Q} 2$, the values of the source voltage and the drain-source voltage relative to $\mathrm{V}_{\mathrm{DD}}$ were respectively $0 \mathrm{~V}$ and $\mathrm{V}_{\mathrm{DD}}-\mathrm{V}_{\text {outDC. }}$. The normalized unit drain current $I_{\text {Du2 }}$ and $V_{G S 2}$ would be derived from the basic equations of the EKV model. The same approach is repeated for the transistor Q3 by taking $\mathrm{V}_{\mathrm{GS} 3}=$ $\mathrm{V}_{\mathrm{DS} 3}=\mathrm{V}_{\mathrm{DS} 2}$.

Similarly for the NMOS transistor Q1, it suffices to set $\mathrm{V}_{\mathrm{S} 1}$ to $0 \mathrm{~V}$ and $\mathrm{V}_{\mathrm{DS} 1}$ to $\mathrm{V}_{\text {outDC }}$ to achieve $\mathrm{I}_{\mathrm{Du} 1}$ and $\mathrm{V}_{\mathrm{GS} 1}$.

Once, all the EKV parameters of the transistors were placed in the dimensioning space, the procedure of finding the dimensions of the transistors according to the predefined specifications of the circuit would start. In this step, the design plan was inspired by the $g_{m} / I_{D}$ methodology.

We begin by determining the value $\mathrm{g}_{\mathrm{m} 2}$ of the transistor Q2 from the gain of the cell and the oscillation frequency. The current of the drain $\mathrm{I}_{\mathrm{D} 2}$ of the transistor $\mathrm{Q} 2$ is subsequently deduced.

The ratio of the drain current $I_{D 2}$ to the unit current $I_{D U 2}$ designates the term $(\mathrm{W} / \mathrm{L})_{2}=(\mathrm{W} / \mathrm{L})_{3}$. The values of the current $\mathrm{I}_{\mathrm{D} 3}$ were obtained referring to the empirical model. The sum of currents $I_{D 3}$ and $I_{D 2}$ gives the current $I_{D 1}$ from which the ratio $(\mathrm{W} / \mathrm{L})_{1}$ is determined.

After determining the widths of the transistors, the program proceeds by calculating the intrinsic capacitances based on the EKV modelling and the extrinsic capacitances via the model developed in [8].

Finally, the calculation of the total load capacity seen at the output of the delay cell was established.

In the last step of this algorithm, the expressions of the circuit specifications as a function of $\mathrm{q}_{\mathrm{F} 1}$ and $\mathrm{q}_{\mathrm{F} 2}$ were introduced. Drawing the graphic contours of the jitter, the area integration and the bias current in the dimensioning space makes it possible to select a point $\left(\mathrm{q}_{\mathrm{F} 10}, \mathrm{q}_{\mathrm{F} 20}\right)$ from which the optimal widths of transistors are determined.

At each solution, the performance of the circuit is calculated and the solutions can be selected according to the circuit specifications.

Fig. 5 illustrates the variation of the jitter (in red color) and the bias current (in blue) in the dimensioning space $\left(\mathrm{q}_{\mathrm{F} 1}, \mathrm{q}_{\mathrm{F} 2}\right)$ for a cell gain equal to 1.5 .

The selected point $\left(\mathrm{q}_{\mathrm{F} 10}, \mathrm{q}_{\mathrm{F} 20}\right)$ from the dimensioning space allows the setting of jitter value at $7.510-11 \mathrm{~s}$ and a bias current value of the order of $1 \mathrm{~mA}$. This point corresponds to a width of the pMOS transistors $\mathrm{W}_{2}=\mathrm{W}_{3}=57.4 \mu \mathrm{m}$ and to a width of the nMOS transistor $\mathrm{W}_{1}=18.2 \mu \mathrm{m}$. These values will be retained in the simulation phase with the ADS tool. 


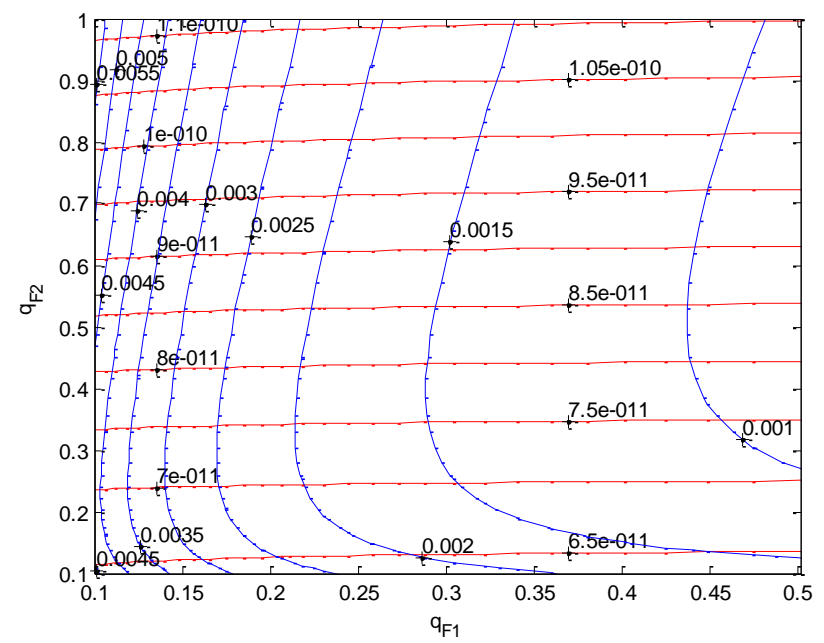

Fig. 5. Graphic contours of jitter and bias current.

\section{SiMULATION RESUlTS AND DISCUSSION}

\section{A. Simulation Results}

The illustrated circuit of Fig. 2 was dimensioned in the previous paragraph for a realization with TSMC $0.18 \mu \mathrm{m}$ technology. In this part, simulations carried out on ADS environment were presented in order to characterize the designed ring VCO in terms of the circuit performances.

Fig. 6 shows the differential output signal Vout-diff obtained by transient analysis under ADS for a bias current $\mathrm{I}_{\mathrm{B}}=1 \mathrm{~mA}$. This signal oscillates at the desired frequency of $433 \mathrm{MHz}$ with amplitude oscillation equal to $0.5 \mathrm{~V}$. Fig. 7 shows the differential output signals for $\mathrm{I}_{\mathrm{B}}=500 \mu \mathrm{A}$ when the signal oscillates at the $374.5 \mathrm{MHz}$ frequency maintaining the oscillation amplitude constant.

The evolution of the oscillation frequency as a function of the bias current $I_{B}$ according to a coarse tuning control was presented in Table I. The tuning range was from $200 \mathrm{MHz}$ to $450 \mathrm{MHz}$. Table II shows the results of a fine tuning control of the VCO. The simulated gain sensibility of $11 \mathrm{MHz} / \mathrm{V}$ was achieved near the central frequency.

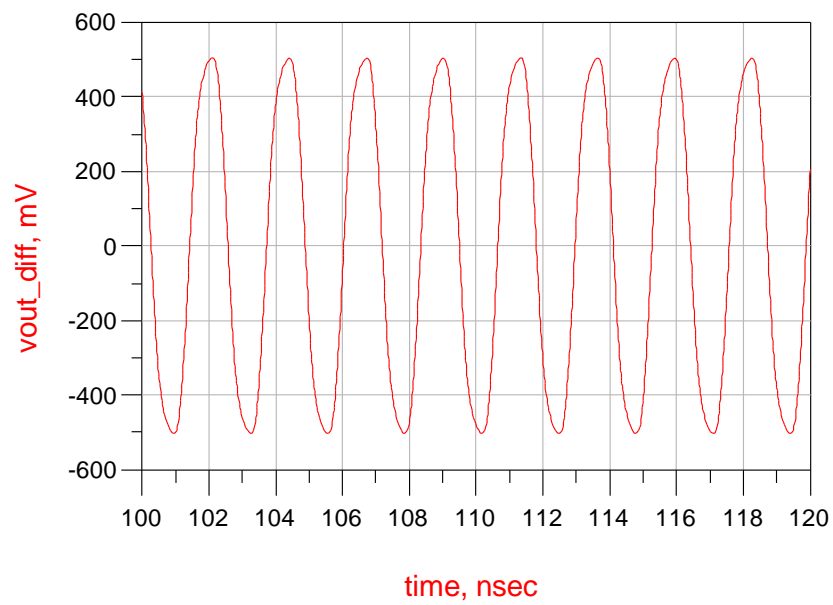

Fig. 6. Output signal for $\mathrm{I}_{\mathrm{B}}=1 \mathrm{~mA}$.

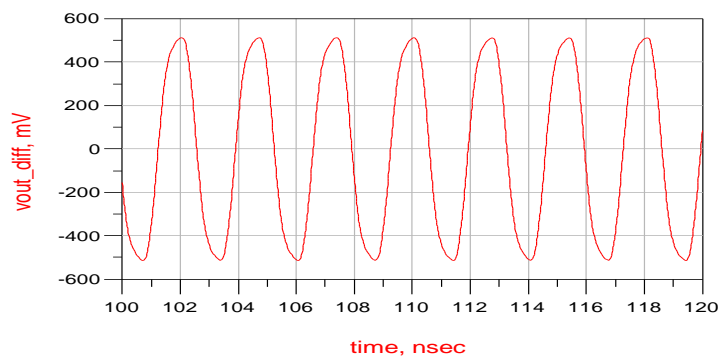

Fig. 7. Output signal for $\mathrm{I}_{\mathrm{B}}=500 \mu \mathrm{A}$.

TABLE I. FREQUENCY OSCILLATION AS A FUNCTION OF BIAS CURRENT

\begin{tabular}{|l|l|}
\hline $\mathbf{I}_{\mathbf{B}}(\boldsymbol{\mu} \mathbf{A})$ & $\mathbf{F}_{\text {osc }}(\mathbf{M H z})$ \\
\hline 200 & 276.2 \\
\hline 300 & 306.7 \\
\hline 400 & 342.5 \\
\hline 500 & 374.5 \\
\hline 600 & 398.4 \\
\hline 700 & 413.2 \\
\hline 800 & 423.7 \\
\hline 900 & 431 \\
\hline 1000 & 432.9 \\
\hline 1100 & 436.7 \\
\hline 1300 & 442.5 \\
\hline 1700 & 450.5 \\
\hline
\end{tabular}

TABLE II. FREQUENCY OSCILLATION AS A FUNCTION OF VCTRL, FIN

\begin{tabular}{|l|l|}
\hline Vctrl,fin (V) & $\mathbf{F}_{\text {osc }}(\mathbf{M H z})$ \\
\hline-0.75 & 413.2 \\
\hline-0.5 & 423.7 \\
\hline-0.25 & 431 \\
\hline 0 & 432.9 \\
\hline 0.25 & 434.8 \\
\hline 0.5 & 436.7 \\
\hline 0.75 & 438.6 \\
\hline
\end{tabular}

Fig. 8 illustrates the simulated phase noise of the VCO through the Pnmx procedure using the harmonic balance method. The phase noise can be noticed as being equal to $107.9 \mathrm{dBC} @ 1 \mathrm{MHZ}$. The power consumption of the designed VCO is of the order of $6.37 \mathrm{~mW}$.

Finally, the use of the eye diagram available in ADS environment allowed us to calculate the temporal jitter of the circuit. Fig. 9 shows the eye diagram found for a VCO output signal oscillating at the $433 \mathrm{MHz}$ frequency. The value of the rms time jitter of the considered circuit is $4.4810-11 \mathrm{~s}$.

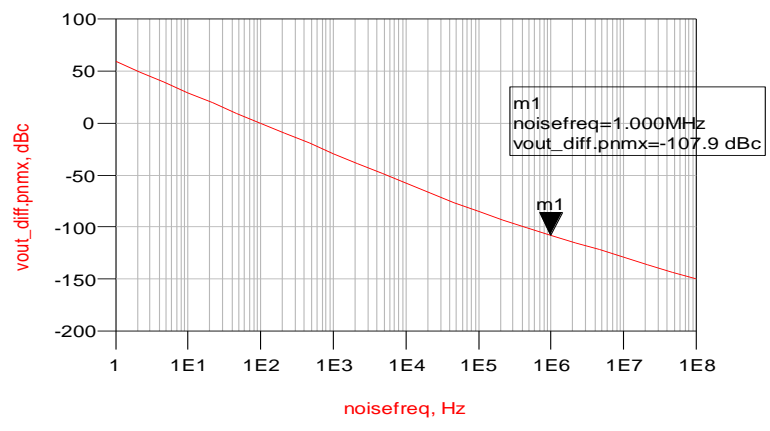

Fig. 8. Phase noise VCO curve. 


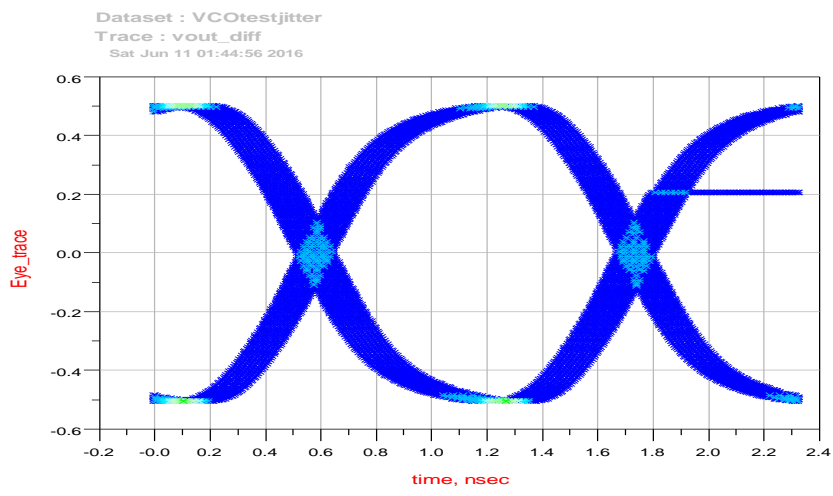

Fig. 9. Eye diagram for a VCO output @ 433MHz.

\section{B. Compartive Study}

Table III provide an overview of the performances of some existing ring VCO. The main fundamental characteristics given for each oscillator are: Technology, frequency coverage, power consumption and phase noise. It is not easy to make a comparison between these different structures as long as the technology used is not the same and as the parameters vary from one to the other. However, it is clear that achieving a high-performance VCO in terms of phase noise involves sacrificing other points such as consumption or favoring frequency coverage with a lower phase noise.

Most publications mentioned in Table III highlight a very high KVCO. Performances in terms of frequency coverage are certainly better, but the oscillator becomes very difficult to drive with a PLL and may create instability of the loop.

The advantage of the VCO realized in the framework of this work is to have a gain $\mathrm{KVCO}=11 \mathrm{MHz} / \mathrm{V}$ resulting from the use of a fine tuning control stage.

Opposite to this work, some circuits do not include the control module of the oscillation amplitude stability.

TABLE III. OVERVIEW OF SOME EXISTING RING VCO PERFORMANCES

\begin{tabular}{|l|l|l|l|l|l|}
\hline Reference & $\mathrm{N}$ & $\begin{array}{l}\text { Technology } \\
(\mu \mathrm{m})\end{array}$ & $\begin{array}{l}\text { Tuning } \\
\text { range } \\
(\mathrm{GHz})\end{array}$ & $\begin{array}{l}\text { Power } \\
\text { consumption } \\
(\mathrm{mw})\end{array}$ & $\begin{array}{l}\text { Phase } \\
\text { noise } \\
(\mathrm{dBc} / \mathrm{Hz})\end{array}$ \\
\hline$[9]$ & 3 & 0.35 & $\begin{array}{l}0.381- \\
1.15\end{array}$ & 7.48 & -126 \\
\hline$[10]$ & 4 & 0.18 & $\begin{array}{l}1.77- \\
1.92\end{array}$ & 13 & -123.4 \\
\hline$[11]$ & 3 & 0.18 & $\begin{array}{l}0.479- \\
4.09\end{array}$ & 10 & -94.08 \\
\hline$[12]$ & 3 & 0.13 & $\begin{array}{l}2.34- \\
3.11\end{array}$ & 2 & -113 \\
\hline$[13]$ & 4 & 0.065 & $\begin{array}{l}485.7- \\
1011\end{array}$ & 10 & -110.8 \\
\hline $\begin{array}{l}\text { This } \\
\text { work }\end{array}$ & 4 & 0.18 & $\begin{array}{l}0.2- \\
0.45\end{array}$ & 6.37 & -107.9 \\
\hline
\end{tabular}

The absence of this module certainly influences the quality of the modulation. Indeed, the variation of the control voltage will be followed not only by a frequency variation but also by a variation of the oscillation amplitude.

In addition, the use of external components in some publications like [9] gives qualities to the integrated circuits in terms of the consumption and noise performance of the circuits. The price to pay is the integration area. The power consumption of the VCO designed as part of this work is $6.37 \mathrm{~mW}$.

This circuit consumes less power compared to the circuits made in the other publications mentioned in Table III with the exception of [12] where the circuit was designed with $0.13 \mu$ technology and powered by a $1.2 \mathrm{~V}$ value voltage.

\section{CONCLUSION AND FUTURE WORK}

In this paper, the design of dual frequency - controlled CMOS ring VCO was studied. An innovative methodology approach based on EKV3.0 modeling for low power VC0 design was presented. The VCO dimensioning algorithm developed with MATLAB was described for a circuit realization with TSMC $0.18 \mu \mathrm{m}$ CMOS technology. The results of simulations carried out under the ADS environment show that the circuit designed oscillates between 200 and 450 $\mathrm{MHz}$ with an amplitude of oscillation equal to $500 \mathrm{mV}$. The simulated jitter is about $44.8 \mathrm{ps}$ and the power consumption of the designed $\mathrm{VCO}$ is $6.37 \mathrm{~mW}$ at $433 \mathrm{MHz}$.

Therefore, the following benefits of this topology could be deduced:

- A high degree of integration considering that no passive element was used.

- A "natural" generation of the phase shift between the signals which leads to a high accuracy in phase and amplitude.

- Good frequency performance, which tends to improve markedly with the introduction of new low gate length CMOS technologies.

This last consideration therefore opens up prospects for our research work and shows that improvements can be made to the architecture presented by the use of advanced technologies. In addition, the future work will be interested to complete the design of the frequency synthesizer.

\section{REFERENCES}

[1] M. Terrovitis, et al. "A 3.2 to $4 \mathrm{GHz}, 0.25 \mu \mathrm{m}$ CMOS frequency synthesizer for IEEE $802.11 \mathrm{a} / \mathrm{b} / \mathrm{g}$ WLAN." in 2004 IEEE International Solid-State Circuits Conference (IEEE Cat. No.04CH37519). 2004.

[2] S.K. Singh, T.K. Bhattacharyya, and A. Dutta. "Fully integrated CMOS frequency synthesizer for ZigBee applications." in 18th International Conference on VLSI Design held jointly with 4th International Conference on Embedded Systems Design. 2005.

[3] L.L.K. Leung, and H.C. Luong. " A 1-V, 9.7mW CMOS frequency synthesizer for WLAN 802.11a transceivers." in Digest of Technical Papers. 2005 Symposium on VLSI Circuits, 2005. 2005.

[4] L.F.Tanguay, Y. Savaria, and M. Sawan. "A $640 \mathrm{~mW}$ frequency synthesizer dedicated to implantable medical microsystems in 90-nm CMOS." in NEWCAS Conference (NEWCAS), 2010 8th IEEE International. 2010. 
[5] J.G. Maneatis, and M.A. Horowitz. " Precise delay generation using coupled oscillators." in Solid-State Circuits Conference, 1993. Digest of Technical Papers. 40th ISSCC., 1993 IEEE International. 1993.

[6] P. Jespers. "The gm/ID Methodology, a sizing tool for low-voltage analog CMOS Circuits: The semi-empirical and compact model approaches." 2009: Springer US.

[7] A. Ayed, M. Lahiani, and H. Ghariani. “ A conversion of empirical model extracted from $180 \mathrm{~nm}$ technology to EKV 3.0 model using MATLAB." International Journal of Advanced Computer Science and Application, 2016. 7(7): p. 85-91.

[8] W. Grabinski, B. Nauwelaers, and D. Schreurs. "Transistor level modeling for analog/RF IC design.” 2006: Springer.

[9] H. Thabet, et al. " A low power consumption CMOS differential-ring VCO for a wireless sensor." Analog Integrated Circuits and Signal Processing, 2012. 73(3): p. 731-740.
[10] Z.Z. Chen, and T.C. Lee. "The Design and Analysis of Dual-Delay-Path Ring Oscillators." IEEE Transactions on Circuits and Systems I: Regular Papers, 2011. 58(3): p. 470-478.

[11] Y.-S. Tiao, M.-L. Sheu, and L.-J. Tsao. "Low-Voltage and High-Speed Voltage-Controlled Ring Oscillator with Wide Tuning Range in $0.18 \mu \mathrm{m}$ Complementary Metal Oxide Semiconductor." Japanese Journal of Applied Physics, 2011. 50(4S): p. 04DE11.

[12] D.Z. Turker, S.P. Khatri, and E. Sanchez-Sinencio. "A DCVSL Delay Cell for Fast Low Power Frequency Synthesis Applications." IEEE Transactions on Circuits and Systems I: Regular Papers, 2011. 58(6): p. 1225-1238

[13] J.M. Kim, et al. "A Low-Noise Four-Stage Voltage-Controlled Ring Oscillator in Deep-Submicrometer CMOS Technology." IEEE Transactions on Circuits and Systems II: Express Briefs, 2013. 60(2): p. 71-75. 